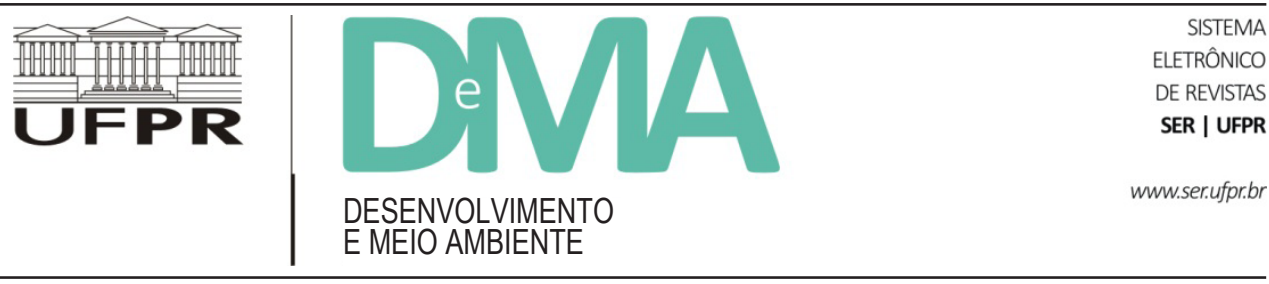

\title{
Decálogo da gestão costeira para Santa Catarina: avaliando a estrutura estadual para o desenvolvimento do Programa Estadual de Gerenciamento Costeiro
}

\section{Decalogue for Coastal Management in Santa Catarina State, Brazil: an Evaluation of the State Coastal Management Program Arrangement}

\author{
Jaqueline ANDRADE ${ }^{1}$, Marinez Eymael Garcia SCHERER ${ }^{2}$ \\ ${ }^{1}$ Arquiteta e Urbanista (UFSC). Mestranda do Curso do Mestrado Profissional em Planejamento Territorial e Desenvolvimento Socioambiental \\ na Universidade do Estado de Santa Catarina (UDESC). E-mail: jaqueaandrade@gmail.com \\ ${ }^{2}$ Doutora em Meio Ambiente e Gestão de Recursos Vivos Marinhos (Universidad de Cádiz). Professora do Departamento de Geociências e do \\ Programa de Pós-Graduação em Geografia da Universidade Federal de Santa Catarina (UFSC). E-mail: marinezscherer@gmail.com
}

Artigo: Recebido em: 8 de abril de 2013; Versão final aceita em: 10 de fevereiro de 2014.

RESUMO O Brasil possui um Programa Nacional de Gerenciamento Costeiro estabelecido há 25 anos, estendendo-se aos 17 estados costeiros brasileiros, sendo Santa Catarina um dos pioneiros. No entanto, apesar do arcabouço jurídico e institucional no âmbito nacional e, mais recentemente, no âmbito estadual, as zonas costeiras brasileira e catarinense vêm se degradando. Destaque é dado para o aumento dos prejuízos por tormentas e inundações nas cidades costeiras; contaminação das águas pela falta de saneamento básico, aumentando os níveis de risco para a saúde humana; concentração da população e da pobreza; perda da biodiversidade; redução da área de habitat crítico e fragmentação dos ecossistemas; dificuldade de acesso dos bens de uso público; aumento dos níveis de risco de acidentes por derramamento de óleo; redução da diversidade de paisagens naturais; erosão da linha de costa entre outros problemas. A lacuna na implantação dos instrumentos previstos pelo Programa Federal e Estadual de Gerenciamento Costeiro, aliada à quase nula avaliação dos processos gerenciais, levam a situações de degradação. Este trabalho avaliou o Programa de Gerenciamento Costeiro do Estado de Santa Catarina, sua estrutura administrativa, financeira e de governança com base em 10 indicadores preestabelecidos pelo Decálogo da gestão costeira. Conclui-se que os aspectos de gestão com maior avanço em Santa Catarina são: Normativas aplicadas ao litoral, Instrumentos de gestão, estabelecimento de Competências, além de Informação disponível. Por outro lado, há aspectos precários e importantes que devem ser tidos como prioritários para o fortalecimento da gestão costeira, sendo eles: definição de uma Política Pública clara, Instituições Públicas, Formação e Capacitação de gestores e comunidade em geral, Educação para a Sustentabilidade, disponibilização de Recursos e Participação Pública.

Palavras-chave: indicadores de gestão; gestão costeira integrada; governança costeira. 
ABSTRACT Brazil has a National Coastal Management Program that was established 25 years ago, extending to the 17 coastal Brazilian states. Santa Catarina was one of the pioneers. However, despite the legal and institutional framework at the national and, more recently, at the state level, Brazilian and Santa Catarina coastal zone have been degrading. Emphasis is given to the increasing damage by storms and flooding in coastal cities; water contamination by poor sanitation, increasing levels of risk to human health; concentration of population and poverty; loss of biodiversity; reduction of critical habitat area and fragmentation of ecosystems; poor access to public use of coastal areas; increased levels of risk of oil spill accidents; reduced diversity of landscapes; erosion of the shoreline; among others. The gap in the implementation of tools provided by the Federal and State Coastal Management Programs combined with almost no evaluation of management processes lead to situations of degradation. This study evaluated the State Coastal Management Program of Santa Catarina: management and financial arrangement and governance system based on 10 pre-established indicators, defined by the Decalogue methodology. We conclude that the management aspects with better advancement in Santa Catarina are: Normative and tools applied to the coast, establishment of responsibilities, as well as information available. On the other hand there is precarious and important aspects that should be given priority to strengthening coastal management: clear definition of Public Policy, Institutions, Education and Training of managers and community, Education for Sustainability, Resources and Public Participation.

Keywords: management indicators; integrated coastal zone management; coastal governance.

\section{Introdução e justificativa}

Para alcançar o objetivo de gestão integrada e utilização racional dos recursos costeiros, o Brasil estabeleceu um programa de gestão costeira. Este programa está baseado na Política Nacional de Meio Ambiente (PNMA) ${ }^{1}$, a qual considera a zona costeira uma área fundamental para a conservação dos recursos vivos, sociais, culturais e paisagísticos, e na Política Nacional para os Recursos do Mar (PNRM) ${ }^{2}$, que tem como um de seus objetivos "incentivar a exploração e o aproveitamento sustentável dos recursos do mar, das águas sobrejacentes ao leito do mar, do leito do mar e seu subsolo, e das áreas costeiras adjacentes".

Embora o Brasil possua um programa estruturado nacionalmente e em implantação desde 1987, como o "Programa Nacional de Gerenciamento Costeiro" (GERCO), contando com uma base legal fundamentada na Lei Nacional de Gerenciamento Costeiro ${ }^{3}$, as ações de operacionalização do GERCO nos estados e municípios da zona costeira são ainda bastante incipientes. Essa falta de execução de fato das ações propostas para uma melhor gestão ambiental da costa tem facilitado a perpetuação de atividades não sustentáveis e a perda gradativa de seus recursos e serviços ambientais (Scherer et al., 2011).

O Programa Nacional de Gerenciamento Costeiro (GERCO) iniciou, tendo participação de seis estados costeiros, com financiamento do Banco Mundial (Barragán, 1998; Moraes, 1999): Rio Grande do Norte, Bahia, Rio de Janeiro, São Paulo, Santa Catarina e Rio Grande do Sul. Atualmente o Programa Nacional de Gerenciamento Costeiro é desenvolvido nos 17 estados costeiros do Brasil, apesar das grandes diferenças entre os estados em relação à implantação do programa.

O Plano Nacional de Gerenciamento Costeiro, atualmente em sua segunda versão (PNGC II), é o principal norteador para a Gestão Costeira no Brasil, sendo o Ministério do Meio Ambiente (MMA) o órgão competente para colocá-lo em prática, com apoio de várias instituições.

No âmbito do Plano Nacional de Gerenciamento Costeiro (PNGC II), o Brasil possui ferramentas para o planejamento e gestão, tais como o Plano de Gestão da

\footnotetext{
${ }^{1}$ A Política Nacional de Meio Ambiente (PNMA) é estabelecida pela Lei Federal no 6.938 de 1981.

${ }^{2}$ A Política Nacional para os Recursos do Mar (PNRM) foi aprovada pelo Decreto Federal no 5.377 de 2005.

${ }^{3}$ A lei nacional que institui o Plano Nacional de Gerenciamento Costeiro é a Lei Federal nº 7.661 de 1988.
} 
Zona Costeira (PGZC); Zoneamento Ecológico-Econômico Costeiro (ZEEC); Plano Estadual de Gerenciamento Costeiro (PEGC); Plano Municipal de Gerenciamento Costeiro (PMGC); Sistema de Informação (SIGERCO); Sistema de Monitoramento (SMA); Relatório de Qualidade Ambiental da Zona Costeira (RQA); Plano de Ação Federal para a Zona Costeira (PAF) e Projeto de Gestão Integrada da Orla Marítima (Projeto Orla). Segundo Vianna et al. (2012), os Planos (nacional, estaduais e municipais) e o PAF são instrumentos gerenciais. Já os outros instrumentos se enquadram, segundo os autores, em operacionais (PGZC, ZEEC, SMA, RQA, Projeto Orla).

Complementares aos instrumentos previstos no PNGC II, o Brasil possui outros programas e políticas públicas que incidem sobre a região costeira, tais como a Agenda Ambiental Portuária, assim como normas setoriais (turismo, pesca, aquicultura, etc.) que são aplicáveis ao litoral.

Segundo o PNGC II, todos os instrumentos devem ser replicados nos estados e municípios. No entanto, há grande dificuldade na aplicação destes instrumentos pelos estados costeiros, com pouca ou nenhuma aplicação de SIGERCO, SMA, RQA e outros. Na realidade brasileira, pouco mais da metade dos estados costeiros apresentam algum instrumento de gerenciamento costeiro, sendo o de maior aplicação o Projeto Orla, seguido do Zoneamento Ecológico Econômico e do Plano Estadual de Gerenciamento Costeiro (Andrade, 2013). Em que pese os 25 anos de GERCO, nenhum estado costeiro possui o Zoneamento Ecológico Econômico Costeiro (ZEEC) e o Plano de Gestão da Zona Costeira (PGZC) completamente implantados, sendo que nenhum possui mecanismos de avaliação das ações gerenciais e da sua estrutura para a gestão costeira. No entanto, alguns estados já se encontram em estágio avançado de implantação do ZEEC (ex.: Pernambuco) (Andrade, 2013).

A não aplicação dos instrumentos de gerenciamento costeiro, aliada ao fato de que nestes últimos anos diversos fatores vêm impondo mudanças de estratégias e de atitudes da comunidade litorânea, a exemplo da aceleração dos efeitos das mudanças climáticas sobre a Zona Costeira, intensificação da exploração do petróleo off shore, aumento do turismo nas áreas litorâneas, perda alarmante de recursos naturais que afetam de forma permanente a produtividade primária, leva a impactos socioambientais de grande magnitude.

Os impactos já são visíveis, com destaque para o aumento dos prejuízos por tormentas e inundações nas cidades costeiras; contaminação dos recursos hídricos e do solo pela falta de saneamento básico; aumento dos níveis de risco para a saúde humana; concentração da população e da pobreza; perda da biodiversidade; redução da área de habitat crítico e fragmentação dos ecossistemas; dificuldade de acesso aos bens de uso público; aumento dos níveis de risco de acidentes, especialmente no setor de petróleo e portos; redução da diversidade de paisagens naturais; erosão da linha de costa (Scherer et al., 2011).

Este cenário de problemas refere-se a uma porção do território brasileiro, considerado Patrimônio Nacional $^{4}$, onde residem em torno de 50 milhões de habitantes, o que corresponde a $26,6 \%$ da população do país (IBGE, 2012), cujo modelo de gestão merece melhorias.

No Estado de Santa Catarina, a zona costeira é composta por 38 municípios costeiros, agrupados em cinco setores litorâneos, estabelecidos no Art. $3^{\circ}$ do Decreto Estadual $n^{\circ} 5.010 / 06$, sendo eles:

I - Setor 1 - Litoral Norte: Araquari, Balneário Barra do Sul, Garuva, Itapoá, Joinville, São Francisco do Sul e Barra Velha;

II - Setor 2 - Litoral Centro-Norte: Balneário Camboriú, Bombinhas, Camboriú, Itajaí, Itapema, Navegantes, Piçarras, Penha e Porto Belo;

III - Setor 3 - Litoral Central: Biguaçu, Florianópolis, Governador Celso Ramos, Palhoça, São José e Tijucas;

IV - Setor 4 - Litoral Centro-Sul: Garopaba, Imaruí, Imbituba, Jaguaruna, Laguna, Pescaria Brava e Paulo Lopes;

V - Setor V - Litoral Sul: Araranguá, Balneário Arroio do Silva, Balneário Gaivota, Balneário Rincão,

\footnotetext{
${ }^{4}$ Art. 225 da Constituição Federal de 1988: $§ 4^{\circ}$ - A Floresta Amazônica brasileira, a Mata Atlântica, a Serra do Mar, o Pantanal Mato-Grossense e a Zona Costeira são patrimônio nacional, e sua utilização far-se-á, na forma da lei, dentro de condições que assegurem a preservação do meio ambiente, inclusive quanto ao uso dos recursos naturais.
} 
Içara, Passo de Torres, Santa Rosa do Sul, São João do Sul e Sombrio.

$\mathrm{Na}$ zona costeira de Santa Catarina residem cerca de 2,5 milhões de pessoas, o que corresponde a $40 \%$ da população do Estado (IBGE, 2012). Assim como em outros estados brasileiros, o panorama de degradação ambiental costeira em Santa Catarina é preocupante. Apesar da evolução da legislação, a acelerada ocupação do litoral dificulta a aplicação dos instrumentos de ordenamento já existentes. Muitos dos problemas atualmente observados na zona costeira poderiam ter sido evitados caso houvessem sido definidos e aplicados critérios de planejamento da ocupação e uso do solo (SPG, 2010a).

Desde 2008 a Secretaria de Planejamento e Gestão do Estado de Santa Catarina (atual Secretaria do Planejamento) foi designada a dar continuidade à implantação do Programa Estadual de Gerenciamento Costeiro. Nos anos de 2009 e 2010, foram desenvolvidos o Zoneamento Ecológico Econômico Costeiro (ZEEC) e o Plano de Gestão da Zona Costeira (PGZC/SC). Uma vez terminados os trabalhos, que estão em fase de apresentação de resultados e rediscussão com os municípios costeiros, Santa Catarina será um dos primeiros estados costeiros do Brasil a apresentar ZEEC e PGZC para todo seu litoral, abrangendo 38 municípios costeiros e 12 milhas náuticas, incluindo um amplo diagnóstico socioambiental (SPG, 2010a).

No entanto, assim como nenhum estado costeiro brasileiro conta com o ZEEC e o PGZC para toda a extensão litorânea, nenhum possui mecanismos de avaliação das ações gerenciais e da sua estrutura para a gestão costeira. A avaliação e o monitoramento das ações de gestão e a maturidade da estrutura administrativa, financeira e de governança são importantes passos para que exista uma melhoria contínua neste processo. Esta avaliação e monitoramento são previstos no ciclo da gestão costeira, amplamente difundido por vários autores (ex.: Gesamp, 1996; Barragán, 2003; Polette \& Silva, 2003), como: 1 - identificação dos problemas; 2 - definição de ações; 3 - adoção formal do Plano; 4 implantação das ações; 5 - monitoramento do sucesso (ou insucesso) destas ações; 6 - avaliação; 7 - retomada do ciclo com identificação dos problemas novamente.

Com a necessidade de se definir parâmetros a fim de avaliar o progresso de programas e projetos de gestão costeira, proposições de avaliação foram pulicadas. Um exemplo é a publicação A manual for assessing progress in coastal management, de Olsen et al. (1999). Neste manual se identificam temas que devem ser avaliados, segundo agências de fomento e organizações internacionais, a fim de estabelecer o grau de maturidade da gestão costeira, tais como: compromisso governamental; marco político/mecanismos legislativos; qualidade da administração; responsabilidades claras; estrutura institucional; uso de informação científica; planificação; tomada de decisões e gestão participativa; resolução de conflitos; sustentabilidade financeira; análise de assuntos-chave; capacidade profissional; educação pública e conscientização; divulgação pública; usos e direitos tradicionais; monitoramento e avaliação ambiental; condições e tendências socioeconômicas e institucionais; transferência de conhecimento/experiência.

Para que a gestão costeira seja colocada em prática, é necessário que exista uma série de pré-requisitos institucionais e de governança. Segundo estudo realizado pela UNEP (1995), os pré-requisitos necessários são: consciência política e pública; existências de estratégias de gestão; conhecimento científico acerca dos ecossistemas e ambientes marinhos e costeiros; reconhecimento dos valores intrínsecos dos recursos costeiros e os potenciais benefícios para o desenvolvimento sustentável; recursos humanos com capacidade de gestão; e apoio financeiro.

$\mathrm{Na}$ última década, a literatura especializada também definiu alguns indicadores estratégicos de gestão costeira e/ou sustentabilidade e governança. Estes indicadores são descritos por Barragán (2004) e Barragán et al. (2008) e corroboram aqueles temas citados por Olsen et al. (1999). Barragán (2004) propõe que existem princípios básicos no processo e estratégias de gestão integrada da zona costeira que devem estar presentes nas estratégias de gestão e políticas públicas. Estes princípios são indicadores com os quais se pode analisar a maturidade e a eficácia desse processo. Estes indicadores fazem parte do decálogo da Gestão Costeira, contendo: 1) Política pública para o litoral; 2) Estrutura normativa; 3) Competências; 4) Instituições públicas; 5) Instrumentos e Estratégias; 6) Formação e Capacitação de gestores e administradores públicos; 7) Recursos Econômicos; 8) Informação e Conhecimento; 9) Educação para a Cidadania; 10) Participação. 
Nesse sentido, um dos primeiros passos para implantar a gestão costeira em um/a município, região, estado ou país é diagnosticar e perceber sua maturidade para a gestão costeira, ou ainda quais elementos estratégicos estão presentes, possibilitando a governança costeira (Barragán et al., 2008).

Um dos desafios atuais que se apresenta ao Programa Estadual de Gerenciamento Costeiro de Santa Catarina é estabelecer estratégias de continuidade institucional do próprio Programa. Assim, o objetivo principal deste trabalho é o de analisar a estrutura e eficácia do processo de gerenciamento costeiro em Santa Catarina. Com base em indicadores previamente testados, é de grande importância para a melhoria da gestão costeira no Brasil e, em especial, no estado catarinense.

\section{Metodologia}

O Programa Estadual de Gerenciamento Costeiro de Santa Catarina (GERCO/SC) e demais iniciativas de gestão costeira existentes no estado, incluindo iniciativas de planejamento e gestão costeira oriundas da sociedade civil organizada, foram analisados neste trabalho com base na metodologia de análise dos indicadores previstos no decálogo (Barragán, 2004).

Essa metodologia foi recentemente aplicada com sucesso pela Rede Ibero-Americana de Manejo Costeiro Integrado (projeto CYTED 2008-2012), resultando em uma publicação de análise das iniciativas de gestão costeira em 13 países Ibero-Americanos (Red Ibermar, 2009), incluindo o Brasil. Arenas-Granados (2012a, 2012b) utilizou-se desta metodologia, assim como no Projeto "Red Española de Gestión Integrada de Áreas Litorales (REGIAL)", financiado pela Fundación Biodiversidad y la Universidad de Cádiz (Sanabria et al., 2011). Gruber et al. (no prelo) também analisaram a gestão costeira no Estado do Rio Grande do Sul à luz do decálogo e Diederichsen et al. (2013) aplicaram a metodologia ao município de Florianópolis.

As iniciativas de gestão foram enquadradas e comparadas aos dez passos para a gestão integrada sugeridos pelo decálogo: 1) Política pública para o litoral - com o objetivo de conhecer se existe uma política institucional estadual sobre a Gestão Costeira Integrada (GCI) que seja explícita e de conhecimento público; 2) Estrutura normativa - com o objetivo de precisar a base normativa que regulamenta a GCI, a gestão de recursos ou as atividades costeiras; 3 ) Competências - com o objetivo de decifrar o esquema de distribuição de responsabilidades públicas em Santa Catarina, em relação à gestão do espaço e recursos costeiros; 4) Instituições públicas - com o objetivo de precisar aquelas instituições públicas mais envolvidas nos assuntos de gestão costeira e marinha em Santa Catarina; 5) Instrumentos e Estratégias - com o objetivo de determinar os instrumentos estratégicos e operativos que interessam à GCI; 6) Formação e Capacitação - com o objetivo de determinar o sistema estadual de capacitação de gestores e administradores públicos vinculados às questões de GCI; 7) Recursos Econômicos - com o objetivo de conhecer as bases econômico-financeiras sobre as quais se sustenta a GCI; 8) Informação e Conhecimento - com o objetivo de determinar o nível de conhecimento existente sobre a zona costeira (físico e natural, social e econômico, jurídico e administrativo), assim como a acessibilidade desta informação; 9) Educação para a Cidadania - com o objetivo de identificar quais são as principais iniciativas de educação relacionadas com a sustentabilidade costeira e marinha, disponíveis para os usuários da zona costeira; 10) Participação - com o objetivo de relacionar a tomada de decisões com a participação cidadã.

Para esta análise, foi realizado um levantamento de dados baseado em pesquisas em documentos oficiais; normas vigentes; planos, programas e projetos governamentais; publicações científicas; sempre buscando avaliar os indicadores propostos. Esta avaliação levou em consideração a presença/ausência do item, assim como sua implantação e eficácia. Salienta-se que parte de informação aqui organizada encontra-se nos Diagnósticos Socioeconômicos dos cinco setores do Litoral de Santa Catarina, disponíveis no sítio virtual do Programa Estadual de Gerenciamento Costeiro ${ }^{5}$.

Após o levantamento de dados, procurou-se estabelecer as fortalezas e debilidades da gestão costeira em Santa Catarina, baseando-se em Botero e Sosa (2011).

\footnotetext{
${ }^{5}$ Disponível em: <http://www.spg.sc.gov.br>.
} 
A cada um dos indicadores atribuiu-se um valor de um (1) a cinco (5), sendo 1 referente a uma situação de avanço precário e 5 como uma situação de avanço dos mais relevantes.

Dessa maneira, procurou-se indicar ações de maior importância para a implantação e desenvolvimento da gestão costeira integrada em Santa Catarina.

\section{Resultados e discussão}

Seguindo a metodologia de análise do decálogo, apresentam-se aqui os resultados para cada indicador de avaliação da maturidade da gestão costeira em Santa Catarina. Alguns tópicos foram agrupados para a apresentação dos resultados.

\subsection{Política pública e Normativa para o litoral}

Santa Catarina segue as diretrizes nacionais do Plano Nacional de Gerenciamento Costeiro (PNGC II) ${ }^{6}$ e tem instituído o Plano Estadual de Gerenciamento Costeiro (PEGC), no escopo do Programa Estadual de Gerenciamento Costeiro (GERCO/SC) ${ }^{7}$.

$\mathrm{O}$ marco legal do GERCO/SC estabelece seus objetivos, além de estratégias, metas e instrumentos para sua implantação no Estado de Santa Catarina. Assim, o programa tem como objetivos:

- Compatibilizar as atividades socioeconômicas e da expansão urbana com as características específicas da Zona Costeira;

- Ordenar as atividades humanas;

- Promover a conservação dos ecossistemas da Zona Costeira considerando a necessidade de desenvolvimento socioeconômico;

- Estabelecer parâmetros e padrões capazes de permitir o controle dos agentes potencialmente causadores de degradação ambiental;

- Fomentar a fixação e o desenvolvimento das populações tradicionais da Zona Costeira;
- Fomentar o desenvolvimento, o planejamento e a gestão das atividades da Zona Costeira de modo integrado, descentralizado e participativo;

- Incentivar a promoção de programas de educação ambiental voltados à conservação dos ecossistemas costeiros;

- Fomentar e apoiar a criação e a manutenção de unidades de conservação na Zona Costeira;

- Apoiar e viabilizar a compatibilização dos instrumentos de planejamento urbano municipais aos instrumentos do GERCO/SC;

- Fomentar e apoiar o desenvolvimento dos Planos Municipais de Gerenciamento Costeiro;

- Sistematizar os dados ambientais.

Apesar de ter sido um dos estados-piloto na primeira fase do GERCO Nacional (final da década de 80), o GERCO/SC não está totalmente implantado. Uma das razões que se pode aventar sobre o não desenvolvimento a contento do GERCO/SC está na falta de uma política estadual para o gerenciamento costeiro de maneira clara, explícita e de conhecimento geral, por não existir também na estrutura de governo. Há uma Lei instituindo o PEGC, mas, em que pese as características de política do PEGC, o mesmo não é considerado como tal, o que não contribui para a melhoria da gestão costeira uma vez que, segundo Barragán (2003), políticas implícitas podem trazer confusão e pouca eficácia. Tampouco há alusão a outras políticas públicas estaduais de base, a exemplo do Plano Nacional de Gerenciamento Costeiro, o qual está baseado na PNMA e na PNRH.

Assim, o Estado de Santa Catarina carece da declaração clara de uma política pública para a gestão da zona costeira que seja economicamente viável e ambientalmente sustentável. Somente com o comprometimento público devidamente institucionalizado e divulgado o GERCO/SC terá condições de alcançar seus objetivos.

Além da lei específica de gerenciamento costeiro, o Estado de Santa Catarina conta com uma gama de instrumentos legais de âmbitos federal e estadual que têm como objetivo a conservação dos recursos naturais, culturais, históricos da zona costeira. Segundo os diagnósticos

${ }^{6}$ O PNGC II foi estabelecido pela Resolução Federal no 005 de 1997/CIRM.

${ }^{7}$ O PEGC é estabelecido pela Lei Estadual no 13.553/05 e regulamentado pelo Decreto Estadual no 5.010/06. 
socioeconômicos do GERCO/SC (SPG, 2010a - 2010e), existem leis e normativas setoriais aplicadas a unidades de conservação marinho-costeiras, portos, pesca e maricultura, uso do solo, turismo, entre outros, sendo elencadas cerca de 400 normas incidentes do litoral catarinense.

No entanto, o conflito entre o progresso da legislação e a velocidade da ocupação antrópica também transparece no que tange à proteção da biodiversidade, diante da degradação de ecossistemas litorâneos como a Floresta Atlântica, a vegetação de restinga e os manguezais (SPG, 2010a - 2010e). Nesse caso, talvez a deficiência na fiscalização pelo Poder Público, e não a ausência de instrumentos legais, tenha tido um papel mais preponderante na configuração atual dos recursos naturais, uma vez que regras relativas à conservação da flora já existem há décadas.

Além disso, Scherer e Emerim (2012) colocam a necessidade de revisão das próprias normas diretamente relacionadas à regulamentação dos instrumentos de gestão costeira no Estado de Santa Catarina, apontando que:

o desenvolvimento do ZEEC tem como premissa as tipologias e enquadramentos de zonas presentes no Anexo I do Decreto 5.010/06. No entanto, os enquadramentos presentes no referido anexo demonstram-se de pouca eficácia e factibilidade na prática. Ao cartografar e produzir o mapeamento do ZEEC, nota-se que muitos enquadramentos não podem ser espacializados, enquanto que outros não correspondem a leis ambientais e urbanas vigentes (Scherer \& Emerim, 2012, p. 1.653).

Os autores seguem colocando que é

importante ressaltar que as tipologias e enquadramento presentes no Anexo I do Decreto 5.010/06 tinham como base o Anexo 1 do Decreto Federal 5.300/04. No entanto, o Anexo 1 do decreto federal não traduz mais o momento histórico da gestão ambiental no país, uma vez que, ao ser aplicado, reflete um diagnóstico da situação atual, não contribuindo, como deveria, para transformar os enquadramentos em cenários de planejamento. Assim, o ZEEC de SC, na primeira fase da implantação do Programa Estadual de Gerenciamento Costeiro, estava pautado na legislação estadual, a qual, por sua vez, está baseada na legislação federal, a qual também não satisfaz como fonte metodológica (Scherer \& Emerim, 2012, p. 1.653).
Assim, urge uma revisão das normas, em especial aquelas que definem os instrumentos e processos de gestão da zona costeira catarinense.

\subsection{Competências e instituições públicas}

Segundo a Lei Nacional de Gerenciamento Costeiro, a gestão costeira deve ser aplicada com a participação da União, dos Estados, dos Territórios e dos Municípios, por intermédio de órgãos e entidades integradas ao Sistema Nacional do Meio Ambiente - SISNAMA.

No âmbito de Santa Catarina, a Lei Estadual $n^{\circ}$ 13.553/05 estabelece que a coordenação do gerenciamento costeiro seria dirigida pela Secretaria de Estado de Desenvolvimento Sustentável, órgão do SISNAMA. O Decreto Estadual ${ }^{\circ} 5.010 / 06$, que regulamenta a Lei Estadual de Gerenciamento Costeiro, em seu Art. $6^{\circ}$ estabelece o mesmo órgão para a coordenação do plano:

O Plano Estadual de Gerenciamento Costeiro será disposto pelo grupo de Coordenação através da Secretaria de Estado de Desenvolvimento Sustentável em estreita colaboração com as Secretarias de Estado de Desenvolvimento Regional, municípios costeiros, a sociedade civil organizada e iniciativa privada (Santa Catarina, 2006, p. 3).

No entanto, a partir da aprovação da Lei Estadual $n^{\circ} 14.465$ de 2008, o órgão governamental responsável pela implantação do Programa Estadual de Gerenciamento Costeiro (GERCO/SC), desde 2008, vem sendo a Secretaria de Estado do Planejamento - SPG, órgão este não vinculado ao SISNAMA. Salienta-se que a equipe da SPG que trabalha com o GERCO/SC, apesar de bastante reduzida, conta com indivíduos com conhecimento de GCI e do histórico do processo em Santa Catarina.

O Conselho Estadual de Meio Ambiente (CONSEMA) possui uma Câmara Técnica do Gerenciamento Costeiro (CTGERCO), que tem a finalidade de avaliar as ações do GERCO/SC. O CONSEMA e a CTGERCO têm em sua composição representantes de diversos órgãos ambientais, sociedade civil organizada e universidades, estando sob a competência da Secretaria de Estado de Desenvolvimento Econômico Sustentável - SDS, sendo este órgão parte do SISNAMA. 
Santa Catarina ainda conta com um Comitê Gestor Integrado para o Planejamento Territorial da Região Costeira - CGI (Decreto Estadual $\left.n^{\circ} 1.591 / 08\right)$. Este comitê responde pelo Grupo de Coordenação disposto na legislação específica. O CGI tem como objetivo articular três programas setoriais em desenvolvimento, abrangendo aspectos ambientais, urbanos e turísticos, integrando compatibilizando e articulando as ações dos programas de:

- Implementação do Programa Estadual de Gerenciamento Costeiro - SPG;

- Elaboração ou revisão de Planos Diretores nos Municípios impactados pela duplicação da Rodovia BR-101, no litoral sul de Santa Catarina, da CODESC; e

- Zoneamento Turístico Ambiental - ZTA - do litoral norte de Santa Catarina, da Secretaria de Estado do Turismo, Cultura e Esporte - SOL.

A coordenação do CGI fica a cargo da SPG e o colegiado é composto por representantes dos segmentos do Poder Público Estadual, Setor Empresarial e Setor Sociolaboral.

Em virtude de o litoral catarinense ser dividido em cinco setores, cada setor conta com uma Secretaria de Estado de Desenvolvimento Regional - SDR, que deve designar um Coordenador do GERCO Regional e seu respectivo suplente para complementar a Coordenação Estadual e atender as necessidades do PEGC no âmbito de cada região e dos municípios que compõem a Zona Costeira. Caberá a eles coordenar junto aos municípios a escolha de representações para integrar os Comitês Temáticos Regionais de Gerenciamento Costeiro CTRs, conforme dispõe o art. $7^{\circ}$ do Decreto Estadual $\mathrm{n}^{\mathrm{o}} 5.010 / 2006$.

Os municípios deverão designar para o Comitê Temático Regional do GERCO-CTR representantes de três setores: governamental, empresarial e sociolaboral. Os setores representativos da sociedade organizada do município deverão escolher seus representantes (titular e suplente) para integrar o Comitê Temático Regional, numa reunião convocada pelos coordenadores regional $\mathrm{e}$ municipal. No entanto segundo Freitas e Adriano (2012):

o decreto que instituiu o comitê gestor integrado, ao ser retificado, fez uma separação de sociedade civil em grupos de interesses: grupo empresarial e grupo sociolaboral, desconsiderando a complexidade da realidade social existente. Ressalta-se ainda que, além da simplificação sofrida frente à representação da sociedade civil, a indicação das mesmas é realizada pela Administração Pública. Entende-se que ainda há uma necessidade de melhoria metodológica na composição desses comitês e que vem sendo discutido junto dentro do CGI (Freitas \& Adriano, 2012, p. 1.384).

Após a indicação dos representantes, cada CTR deverá ser homologado pelo respectivo Conselho de Desenvolvimento Regional ao qual deverá pertencer. Dos cinco CTRs que deveriam existir, quatro foram constituídos e homologados, mas nenhum destes está em pleno funcionamento. Ou seja, o esquema de participação através dos Comitês Temáticos Regionais do GERCO CTRs - não parece estar cumprindo sua função.

Dessa maneira, o Estado de Santa Catarina pretende incentivar a cooperação e a coordenação entre os diferentes setores governamentais e da sociedade civil na gestão costeira integrada.

Ainda, segundo SPG (2010a), no que tange aos órgãos de licenciamento ambiental, o Estado de Santa Catarina conta com a Fundação de Meio Ambiente FATMA. Nesta questão de licenciamento e fiscalização, órgãos de abrangência nacional também atuam no estado em temas de interesse nacional, tais como licenciamentos de empreendimentos que afetem cursos de água em divisa de dois estados, de empreendimentos que ocupem áreas da união, unidades de conservação federais, ou mar territorial. Dentre os órgãos nacionais citam-se o Instituto Brasileiro do Meio Ambiente e dos Recursos Naturais Renováveis (IBAMA), o Instituto Chico Mendes de Conservação da Biodiversidade (ICMBio), a Secretaria do Patrimônio da União (SPU), a Capitania dos Portos e o Instituto do Patrimônio Histórico e Artístico Nacional (IPHAN).

Complementarmente, muitos municípios do Estado de Santa Catarina possuem órgãos ambientais e de ordenamento do uso do solo e de atividades ligadas à pesca e/ou à maricultura.

Existe ainda uma série de órgãos governamentais e instâncias consultivas e/ou deliberativas que, direta ou indiretamente, têm influência nos diferentes setores de 
usos e atividades da Zona Costeira catarinense. Dentre estes, de âmbito federal, citam-se o Ministério do Turismo, relacionado ao turismo e desenvolvimento urbano; o Ministério da Pesca e Aquicultura, relacionado às atividades de pesca e aquicultura; e a Secretaria Especial de Portos, referente às atividades portuárias. Já no âmbito estadual, exemplifica-se com a Secretaria de Estado de Turismo, Cultura e Esporte, vinculada ao turismo, e a Empresa de Pesquisa Agropecuária e Extensão Rural, relacionada à pesca, aquicultura e agricultura. No entanto, a integração entre estes órgãos não ocorre, levando à fragmentação das decisões gerenciais e dos recursos.

\subsection{Instrumentos e Estratégias}

Dentro da ótica de unidade federativa, o GERCO/ $\mathrm{SC}$ apresenta as mesmas diretrizes e instrumentos do Programa Nacional de Gerenciamento Costeiro. Desta forma, seus instrumentos compreendem: o Plano Estadual de Gerenciamento Costeiro (PEGC); o Zoneamento Ecológico Econômico Costeiro - ZEEC; o Plano de Gestão da Zona Costeira - PGZC; o Sistema de Informações do Gerenciamento Costeiro - SIGERCO; o Sistema de Monitoramento Ambiental - SMA/ZC; o Relatório de Qualidade Ambiental - RQA/ZC; e o Projeto de Gestão Integrada da Orla Marítima - Projeto Orla (Lei Estadual $\left.\mathrm{n}^{\mathrm{o}} 13.533 / 2005\right)$.

No entanto, há que se ressaltar que o Estado de SC tem o PEGC instituído por lei pertinente, mas não desenvolvido. No Artigo $4^{\circ}$ da Lei Estadual de Gerenciamento Costeiro ${ }^{8}$ observa-se que:

O Plano Estadual de Gerenciamento Costeiro - PEGC - será elaborado e, quando necessário, atualizado, pelo Poder Executivo, na instância técnico-administrativa de um Grupo de Coordenação dirigido pela Secretaria de Estado do Planejamento, cuja composição e forma de atuação serão definidas no decreto regulamentar a que se refere o art. 10 desta Lei (Santa Catarina, 2005, p. 2).
Até o momento alguns instrumentos de gestão estão sendo elaborados, mas o PEGC não foi devidamente desenvolvido e implantado.

Em relação aos outros instrumentos de gestão previstos no GERCO, Santa Catarina desenvolveu em 1995 um Diagnóstico Ambiental do Litoral, mediante convênio com o IBGE. A partir deste diagnóstico, foi desenvolvido o Plano Estadual de Gerenciamento Costeiro em 1996, o qual não teve continuidade das ações. O Estado também possui um estudo de Zoneamento Ecológico Econômico Costeiro - ZEEC - para o Setor 2 (Litoral Centro-Norte). O mesmo setor também possui um estudo com definições de planejamento.

Nos anos de 2009 e 2010 foram desenvolvidos o Zoneamento Ecológico Econômico Costeiro (ZEEC) e o Plano de Gestão da Zona Costeira (PGZC/SC) para todo o litoral catarinense. Atualmente estes estudos estão em fase de apresentação de resultados e rediscussão com os municípios costeiros. Após esta fase, deverão ser avaliados e ratificados pelo Conselho Estadual de Meio Ambiente (CONSEMA).

Já para a implantação do Projeto Orla, o Estado apresenta uma Comissão Técnica Estadual do Projeto Orla (CTE Orla) ${ }^{9}$, tendo este instrumento um caráter de planejamento participativo, apresentando como objetivos articular, juntamente com a Comissão Técnica Estadual, políticas estaduais incidentes na orla; selecionar municípios catarinenses litorâneos prioritários e aptos a participar do Projeto Orla; supervisionar os planos de intervenção municipal; fornecer apoio técnico no desenvolvimento de ações pertinentes ao Projeto Orla; propor ações integradas de intervenção da orla. Atualmente oito municípios estão desenvolvendo o Projeto de Gestão Integrada da Orla Marítima no Estado, sendo que três deles possuem um comitê gestor e já entregaram os Planos de Gestão Integrada (PGI) para o Comitê Técnico Estadual ${ }^{10}$.

Recentemente, o Estado desenvolveu diagnósticos socioeconômicos dos cinco setores costeiros, propostas

\footnotetext{
${ }^{8}$ A lei Estadual de Gerenciamento Costeira (Lei Estadual no 13.553/05) institui o Plano Estadual de Gerenciamento Costeiro

${ }^{9}$ O Projeto Orla é definido pelos Decretos Estaduais n ${ }^{\circ} 3.007 / 04$ e n ${ }^{\circ} 4.033 / 04$.

${ }^{10}$ Informação fornecida pela Coordenadora do Projeto Orla em Santa Catarina/SPU.
} 
de ZEEC e planos de gestão por setores e um com programas e ações regionais.

A atual situação do Estado de Santa Catarina frente aos instrumentos de gerenciamento costeiro estabelecidos é a descrita na Tabela 1 .

TABELA 1 - ESTADO ATUAL DE DESENVOLVIMENTO/IMPLANTAÇÃO DOS INSTRUMENTOS DE GERENCIAMENTO COSTEIRO NO ESTADO DE SANTA CATARINA

\begin{tabular}{|l|c|c|c|}
\hline & $\begin{array}{c}\text { Não desenvol- } \\
\text { vido/ implan- } \\
\text { tado }\end{array}$ & $\begin{array}{c}\text { Em fase de } \\
\text { desenvol- } \\
\text { vimento }\end{array}$ & $\begin{array}{c}\text { Implan- } \\
\text { tado e } \\
\text { operante }\end{array}$ \\
\hline $\begin{array}{l}\text { Lei Estadual de } \\
\text { Gerenciamento } \\
\text { Costeiro }\end{array}$ & & $\mathrm{X}$ \\
\hline PEGC & & $\mathrm{X}$ & \\
\hline ZEEC & & $\mathrm{X}$ & \\
\hline PGZC & & $\mathrm{X}$ & \\
\hline SIGERCO & $\mathrm{X}$ & $\mathrm{X}$ & \\
\hline SMA/ZC & $\mathrm{X}$ & & \\
\hline RQA/ZC & $\mathrm{X}$ & & \\
\hline Projeto Orla & & $\mathrm{X}$ & \\
\hline
\end{tabular}

FONTE: Atualização de quadro apresentado em SPG, 2010c, p. 276.

Além dos instrumentos formalizados pelo GER$\mathrm{CO} / \mathrm{SC}$, existem outros instrumentos estratégicos sendo utilizados para a gestão da zona costeira. Entre eles destacam-se: as unidades de conservação costeiro-marinhas, sendo cinco federais, cinco estaduais, 41 municipais e oito reservas particulares (SPG, 2010a-2010e); e os Planos Locais de Desenvolvimento da Maricultura (PLDM).

\subsection{Formação e Capacitação}

Santa Catarina conta com diversas universidades e centros de pesquisa e ensino que têm o potencial de albergar atividades de formação e capacitação de recursos humanos para atuarem na gestão integrada costeira. Há seis anos foi criado o curso de Oceanografia na Universidade Federal de Santa Catarina, o qual conta com uma disciplina de Gerenciamento Costeiro. Da mesma maneira, a Universidade do Vale do Itajaí (UNIVALI) também possui o curso de Oceanografia com disciplina similar. Ressalta-se também o curso de Administração Pública da Universidade Estadual de Santa Catarina (UDESC).

Outros cursos acadêmicos têm o potencial de contribuir para a formação de gestores costeiros, como aqueles na área de administração e políticas públicas. No entanto, atualmente não existem cursos que tenham como objetivo capacitar e/ou formar gestores e administradores públicos vinculados à GCI. A gestão costeira é ainda vista de maneira compartimentada e setorial, sendo o objeto (subsistemas físico-natural, socioeconômico, jurídico-administrativo) bem estudado, mas o estudo do objetivo (gestão costeira integrada) (Barragán, 2003) não encontra campo de desenvolvimento no Estado de Santa Catarina.

Os gestores públicos, assim como a sociedade civil, não encontram bases de formação para atuar no gerenciamento costeiro, seja nos processos decisórios ou nos fóruns de participação cidadã.

\subsection{Recursos}

Apesar da importância da zona costeira para o Estado de Santa Catarina, não existe um fundo destinado a ações de gestão deste espaço. Recursos para a implementação dos programas e projetos de gestão, elencados nos Planos de Gestão da Zona Costeira catarinense, deverão ser captados em diferentes fundos (internacionais, federais e/ou estaduais), além de recursos da iniciativa privada.

No entanto, o Plano Plurianual do Estado de Santa Catarina (PPA/SC) para os anos 2008/2011 estipulava o montante de R $\$ 1.000 .000,00$ para a elaboração e gestão do Plano Estadual de Gerenciamento Costeiro. Valor este que não foi totalmente utilizado para tal fim, haja vista que a contratação de equipe, via licitação, para o desenvolvimento do ZEEC e do PGZC de Santa Catarina, foi formalizada por valor inferior. Atualmente, o PPA/SC (2013/2015) não prevê recurso algum para a estruturação e melhora da gestão costeira.

Como agravante, analisando os recursos humanos disponíveis, vê-se que a equipe técnica responsável pelo gerenciamento costeiro do Estado, no ano de 2010, 
contava somente com um arquiteto responsável, diretor da Diretoria de Cidades e um geógrafo responsável pelo Projeto Orla. Eventualmente, a equipe recebia reforços de estagiários e pessoas de outros setores. Assim, para desenvolver o ZEEC de todo o litoral, bem como os Planos de Gestão, uma empresa consultora foi contratada.

Atualmente (2013), a equipe é bastante reduzida, sendo que a Secretaria de Planejamento passa por reestruturação e espera-se que a equipe para o GERCO/SC seja incrementada.

\subsection{Informação}

Santa Catarina conta com universidades com grande produção de conhecimento da zona costeira. Destaque para a Universidade Federal de Santa Catarina (UFSC), que recentemente criou um curso de Oceanografia, assim como a Universidade do Vale do Itajaí (UNIVALI), que possui este mesmo curso há 10 anos. Cursos de Geografia, Biologia, Engenharia Ambiental, Arquitetura e Urbanismo, Direito, Sociologia e outras matérias de interesse também são ofertados ao longo do litoral, havendo, no entanto, uma concentração de produção científica nos Setores Centro (Setor 3) e Centro-Norte (Setor 2).

Apesar de haver uma produção científica razoável, a compilação de dados para o desenvolvimento dos diagnósticos socioeconômicos do litoral (SPG, 2010a-f) demonstrou lacuna de conhecimento em diversas áreas, em especial aquelas relacionadas ao conhecimento do mar e seus recursos, e com maior intensidade a falta de conhecimento dos ambientes localizados no sul do Estado. Falta de conhecimento organizado e disponível ficou evidente também na área de unidades de conservação, principalmente as municipais, sítios históricos e áreas indígenas.

Além da lacuna de conhecimento, aquele já produzido não se encontrava disponível de maneira sistematizada e organizada até a publicação dos diagnósticos socioambientais pela SPG (2010a - 2010e). Nesse sentido, Santa Catarina deu um passo ao coletar informação dispersa nos vários centros de pesquisa e ensino, instituições e organizações, e disponibilizar essa informação na página de internet da SPG. Dessa maneira, diagnósticos produzidos apontaram as lacunas no conhecimento, organizaram e sistematizaram a informação existente e esta informação foi disponibilizada de maneira eletrônica para qualquer cidadão. No entanto, a atualização e compilação dessa informação não deve ser estanque, necessitando de constante trabalho de pesquisa e sistematização.

\subsection{Educação para a sustentabilidade}

Neste item, Santa Catarina ainda está bastante aquém do desejável. Existem iniciativas isoladas de produção de material educativo com relação à zona costeira e a apresentação deste material de maneira formal (escolas) e informal é bastante precária.

Destaque deve ser dado às produções da Universidade do Vale do Itajaí, procedentes do Centro de Ciências Tecnológicas, da Terra e do Mar-CTTMAR. Por meio deste centro de pesquisa, foram desenvolvidas cartilhas sobre a zona costeira e segurança nas praias.

Em 2005, o governo estadual aprovou a Política Estadual de Educação Ambiental, sendo em 2006 aprovado um dos instrumentos desta política, o Programa de Educação Ambiental (ProEEA-SC). Segundo Andrade et al. (2012), este programa foi

elaborado pela Secretaria de Estado do Desenvolvimento Econômico Sustentável - SDS - tendo como desafio a construção de um caminho em conjunto com seus parceiros que leve a um novo modelo de Educação Ambiental, com planejamento estratégico bem desenhado, para que alcance resultados à médio e longo prazo na prática (Andrade et al., 2012, p. 1.606).

Este programa, no momento, está em fase de implantação.

No entanto, não existe uma iniciativa no escopo da gestão costeira de educação para a sustentabilidade costeira e marinha em Santa Catarina. Nenhuma ação neste sentido tem sido coordenada pela SPG ou Secretaria de Educação do Estado.

\subsection{Participação}

A participação no processo da gestão costeira tem o objetivo de relacionar a tomada de decisões com a 
participação cidadã. Freitas e Adriano (2012) enfatizam que a previsão da participação social não é apenas um dispositivo específico e sim um princípio estrutural da sociedade brasileira, instituído pela própria Constituição Federal de 1988, caracterizando um Estado Constitucional Democrático de Direito.

A atual lei estadual de gerenciamento costeiro prevê que o processo participativo deve ser baseado na representatividade dos comitês temáticos de gerenciamento costeiro. Tais comitês foram criados dentro dos Conselhos regionais de desenvolvimento costeiros com representação do Governo do Estado, dos Municípios e da Sociedade Civil organizada, com sede e atuação no setor costeiro, de acordo com o estipulado pelo Decreto Estadual $\mathrm{n}^{\circ}$ 5.010/06.

Tendo em vista tanto esta normativa estadual quanto a normativa federal, Freitas e Adriano (2012, p. 1.383 ) entendem que estas normas "parecem estar preocupadas em garantir a presença de instrumento jurídico que contemple o princípio constitucional para abarcar a participação". Observam ainda que há uma dificuldade metodológica tanto frente à participação popular direta quanto representativa da sociedade. Também segundo Freitas e Adriano (2012, p. 1.383), “o que se denota das normatizações é que foi enfatizado procedimento de caráter mais tecnicista, albergado pela participação meramente representativa da chamada sociedade civil".

Scherer e Emerim (2012) também apontam falhas no processo de participação pública durante a fase de desenvolvimento do ZEEC e do Plano de Gestão (2009 a 2010), pois, segundo os autores:

apesar de haver sido montada uma estrutura participativa para que houvesse representatividade dos diferentes setores da sociedade civil e órgãos governamentais nas discussões no desenvolvimento dos instrumentos, notou-se uma baixa participação. Mesmo representantes das prefeituras tiveram pouca participação, sendo que as presenças se resumiam a defender posições isoladas, não havendo espaço para uma discussão regional. Neste sentido, avalia-se a necessidade de uma maior cultura e consciência participativa da comunidade costeira catarinense, além da conformação e implantação de canais de participação real e efetiva (Scherer \& Emerim, 2012, p. 1.652).
Assim, conclui-se que, apesar de haver sido desenhado um mecanismo de participação, contando com os Comitês Técnicos Regionais, conforme explanado no item Competências e Instituições Públicas, ajustes devem ser realizados com o objetivo de garantir a participação e a presença de diferentes atores sociais nas tomadas de decisão.

Ressalta-se também que a falta de educação para a sustentabilidade e formação de pessoas acaba refletindo na cultura participativa da população em geral, sendo que a participação efetiva fica atrelada ao bom conhecimento dos ambientes naturais e dos processos de gestão estabelecidos.

Considerando os indicadores a fim de estabelecer as fortalezas e debilidades, foi possível valorar os aspectos da gestão costeira no Estado de Santa Catarina, conforme descrito na metodologia. A cada um dos indicadores atribuiu-se um valor de um (1) a cinco (5), sendo 1 referente a uma situação de avanço precário e 5 como uma situação de avanço dos mais relevantes.

Pelos resultados aferidos, não se entende que haja uma situação de avanço relevante na gestão costeira em Santa Catarina de maneira global (Tabela 2). No entanto, alguns aspectos demonstraram maior avanço nos últimos anos, tais como: Normativa para o litoral, Instrumentos, Estabelecimento de Competências, e Informação. Por outro lado, há aspectos importantes que devem ser revistos como ações prioritárias para o fortalecimento da gestão costeira, sendo eles: Definição de uma Política Pública de maneira clara, fortalecimento das Instituições Públicas, Formação e Capacitação de gestores costeiros, Educação para a Sustentabilidade, disponibilização de Recursos e melhoria da Participação Pública.

A partir da análise do quadro apresentado, procurou-se indicar ações que seriam prioritárias para a implantação e desenvolvimento da gestão costeira integrada em Santa Catarina, no que diz respeito à institucionalização e governança da gestão. Assim, citam-se, na continuação, as ações elencadas, algumas das quais refletem o Plano de Gestão Regional desenvolvido para a zona costeira (SPG, 2010f):

- Definição e publicação de uma Política Pública para a Gestão Costeira;

- Divulgação das normas e documentos de gestão costeira existentes; 
TABELA 2 - ANÁLISE QUANTITATIVA E QUALITATIVA DOS ITENS DO DECÁLOGO PARA SANTA CATARINA

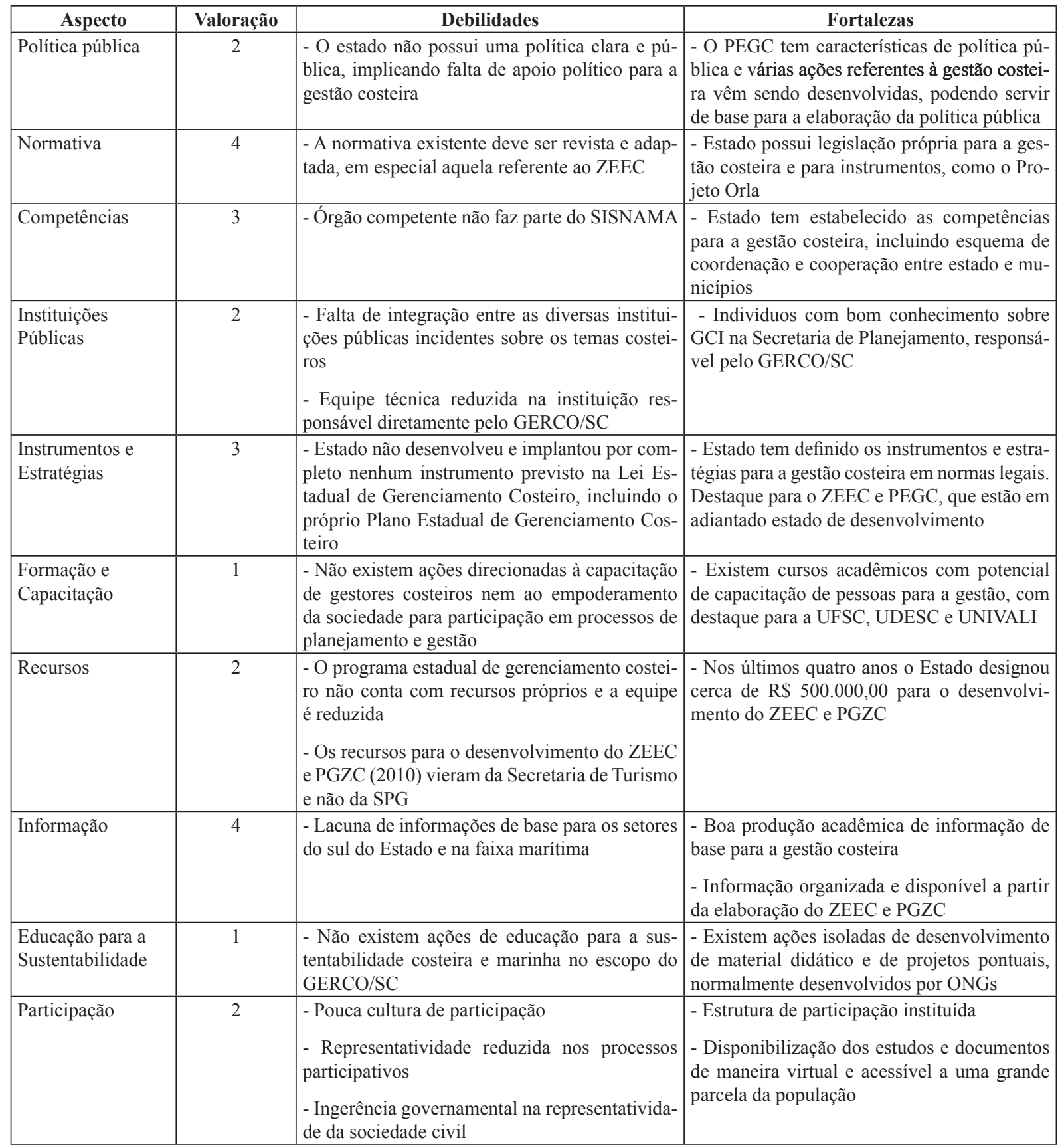

FONTE: Elaboração própria (2013) 
- Estruturação da Equipe para o Gerenciamento Costeiro do Estado de Santa Catarina (GERCO/ $\mathrm{SC})$;

- Disponibilização de recursos financeiros para garantir a continuidade do GERCO/SC e a aplicação da legislação pertinente à zona costeira;

- Revisão da base legal para o Gerenciamento Costeiro;

- Desenvolvimento de todos os instrumentos de gestão definidos legalmente;

- Estabelecimento de programas de capacitação continuada para técnicos e gestores costeiros;

- Incentivo à produção de conhecimento técnico e científico, em especial nos setores 4 e 5;

- Desenvolvimento de um programa de educação para a sustentabilidade costeiro-marinha;

- Implantação de mecanismos de comunicação e participação pública eficazes e representativos.

\section{Considerações finais}

A zona costeira é uma área de relevante importância para o Brasil e para Santa Catarina, quer seja pela riqueza de ecossistemas e recursos naturais, quer seja pela grande quantidade de atividades econômicas que são desenvolvidas nessa região.

A gestão desse espaço e a necessidade de resolução de conflitos que existem pelo grande número de usuários devem ser parte da estratégia nacional e dos estados costeiros para o desenvolvimento socioeconômico e ambiental. Como parte primordial desta estratégia deve figurar a avaliação constante dos processos de gestão, de maneira a contribuir para a gestão integrada, adaptativa e com melhoria contínua.

Ao se realizar esta análise, percebe-se que a gestão costeira no Estado de Santa Catarina carece de estruturação institucional, estando em um estágio inicial de desenvolvimento. Apesar de haver arcabouço legal para o desenvolvimento de instrumentos previstos para a gestão costeira, existe pouco apoio político/institucional ao Programa, o que se traduz em poucos recursos, equipe técnica reduzida, ausência de uma agenda governamental para a implantação da gestão costeira e pouco incentivo à participação cidadã.

Assim, as ações devem ser focadas na estruturação dos processos de planejamento e gestão integrados e participativos, priorizando aquelas ações estratégicas, tais como: política pública definida e praticada, normas claras e adequadas, competências definidas, capacitação institucional e de gestores, empoderamento da sociedade civil, processos participativos apropriados e legítimos, incentivo ao desenvolvimento e divulgação de informação pertinente. Convém ressaltar que esta priorização é necessária, pois o desenvolvimento de instrumentos sem a devida estruturação política e administrativa pode levar a uma fraca implantação dos mesmos, o que, infelizmente, vem ocorrendo ao longo dos 25 anos de história do GERCO nacional e estadual/SC.

Barragán Muñoz, J. M. (Coord.). Manejo costero integrado en Iberoamérica: diagnóstico y propuestas para una nueva política pública. Cádiz-ES: Red Ibermar (CYTED), 2012a. p. 21-68.

. Manejo costero integrado y sustentabilidad en Iberoamérica: un análisis propositivo de políticas públicas en las dos caras atlánticas: España, Portugal, Colombia y Panamá. Cádiz-ES: Editorial Académica Española, 2012b. 410 p.

Barragán, J. M. M. La ordenación del espacio litoral brasileño: el Plan Nacional de Gestión Costera (PNGC). Anales de Geografia de la Universidade Complutense, 18, 89-114, 1998. 
. Medio ambiente y desarrollo en áreas litorales: introducción a la planificación y gestión integradas. Cádiz-ES: Universidad de Cádiz, Servicio de Publicaciones, 2003.306 p.

. Las áreas litorales de España. Del análisis geográfico a la gestión integrada. Barcelona: Editorial Ariel S.A., 2004. $214 \mathrm{p}$.

; Ruiz, A. J. C.; Cayero, M. L. P. Estrategia andaluza de gestión integrada de zonas costeras. Consejería de Medio Ambiente, Junta de Andalucía, 2008. 255 p.

Botero, C. S.; Sosa, Z. T. Propuestas para la gestión litoral de un país con tres costas: Colombia. In: Barragán Muñoz, J. M. Manejo costero integrado y politica pública en Iberoamérica: propuestas para la acción. Cádiz-ES: Red Ibermar (CYTED), 2011. 280 p. ISBN 13: 978-84-694-4844-1.

Brasil. Lei $n^{\circ} 7.661$, de 16 de maio de 1988. Institui o Plano Nacional de Gerenciamento Costeiro e dá outras providências. Brasília: D.O.U. de 18.5.1988. 1988.

Decreto $n^{\circ} 5.300$ de 7 de dezembro de 2004. Regulamenta a Lei $\mathrm{n}^{\circ} 7.661$, de 16 de maio de 1988, que institui o Plano Nacional de Gerenciamento Costeiro - PNGC, dispõe sobre regras de uso e ocupação da zona costeira e estabelece critérios de gestão da orla marítima, e dá outras providências. Brasília: D.O.U. de 8.12.2004.

Diederichsen, S. D.; Gemael, M. K.; Hernande, A. de O.; de Oliveira, A. de O.; Paquette, M.; Schmidt, A. D.; Silva, P. G. da; Silva, M. S. da; Scherer, M. E. G. Gestão costeira no município de Florianópolis, SC, Brasil: um diagnóstico. Revista da Gestão Costeira Integrada, 13(4), 499-512, 2013. DOI:10.5894/rgci425.

Freitas, M.; Adriano, M. Z. Participação popular no gerenciamento costeiro de Santa Catarina Brasil. In: Anais del I Congreso Iberoamericano de Gestión Integrada de Áreas Litorales. Cádiz - Espanha, 2012. p. 1378-1388.

GESAMP. The Contributions of Science to Coastal Zone Management. Rep. Stud. GESAMP, IMO/FAO/UNESCOIOC/WMO/WHO/IAEA/UN/UNEP Joint Group of Experts on the Scientific Aspects of Marine Environmental Protection. 61: 66, 1996.

Gruber, N. L. S.; Arenas, P.; Barragán, J. M.; Ayup-Zouain, R. N.; Scherer, M.; Strohaecker, T. Análise propositva do Decálogo para Gestão Integrada das Zonas Costeiras no Rio Grande do Sul, Brasil, como tema para debate em Governança. In: Problemática de los ambientes costeros: Sur de Brasil, Uruguay y Argentina. 2 . UNESCO. Ed. Montevideo, v. 2. No prelo.
IBGE. IBGE em parceria com a Marinha do Brasil lança o Atlas Geográfico das Zonas Costeiras e Oceânicas. 2012. Disponível em: <http://www.ibge.gov.br/home/presidencia/noticias/noticia_visualiza.php?id_noticia $=2036 \& i d \_p a g i n a=1>$.

Moraes, A. C. R. de. Contribuições para a gestão da zona costeira do Brasil. Elementos para uma geografia do litoral brasileiro. São Paulo: Hucitec/Edusp, 1999. 229 p.

Olsen, S. B.; Lowry, K.; Tobey, J. A. Manual for Assessing Progress in Coastal Management. The University of Rhode Island. Coastal Resources Center, Graduate School of Oceanography, Narragansett, RI 02882 USA. 61 p. 1999.

Polette, M.; Silva, L. P. Gesamp, Icamp e PNGC - Análise comparativa entre as Metodologias de Gerenciamento Costeiro Integrado. Ciênc. Cult., Revista da Sociedade Brasileira para o Progresso da Ciência, São Paulo, 55(4), out.dez. 2003.

Red Ibermar - Rede Iberoamericana de Manejo Costero Integrado. Manejo costero integrado y política pública en Iberoamérica: un diagnóstico. Necesidad de cambio. Coordinador: Juan Manuel Barragán Munõz. Editores: Pedro Arenas Granados, Juan Adolfo Chica Ruiz, Javier García Onetti y Javier García Sanabria. CYTED-SEGIB. Espanha, 2009.

Sanabria, J. G.; Onetti, J. G.; Barragán, J. M. M. Las comunidades autónomas y la gestión integrada de las áreas litorales de España. Materiales para un debate sobre gobernanza. Cádiz-ES: Grupo de Investigación en Gestión Integrada de Áreas Litorales de la Universidad de Cádiz, 2011. 337 p. ISBN: 978-84-695-1402-3.

Santa Catarina. Lei $n^{\circ} 13.553$ de 16 de novembro de 2005. Institui o Plano Estadual de Gerenciamento Costeiro. Palácio Barriga Verde. Florianópolis, SC. Alterada pelas Leis: 14.465/08; 14.736/09.

. Decreto $n^{\circ} 5.010$, de 22 de dezembro de 2006. Regulamenta a Lei $\mathrm{n}^{\mathrm{o}} 13.553$, de 16 de novembro de 2005. Florianópolis, 22 de dezembro. DOSC de 22.12.2006.

Scherer, M.; Asmus, M.; Filet, M.; Sanches, M.; Poleti, A. E. El manejo costero en Brasil: análisis de la situación y propuestas para una posible mejora. In: Farinós Dasí, J. (Ed. y Coord.). La Gestión Integrada de Zonas Costeras ¿Algo más que una Ordenación del Litoral Revisada? La GIZC como evolución de las prácticas de planificación y gobernanza territoriales. N. 9. Valencia: PUV/IIDL, 2011. (Colección "Desarrollo Territorial").

Scherer, M.; Emerim, E. Implantação dos instrumentos do Programa Estadual de Gerenciamento Costeiro de Santa Catarina: uma análise. In: Anais do I Congreso Iberoamericano 
de Gestión Integrada de Áreas Litorales. Cádiz, Espanha, 2012. p. 305-314.

SPG - Secretaria de Planejamento e Gestão do Estado de Santa Catarina. Implantação do Plano Estadual de Gerenciamento Costeiro: Diagnóstico Socioambiental - Setor Litoral Central. SC, 2010a.

Implantação do Plano Estadual de Gerenciamento Costeiro: Diagnóstico Socioambiental - Setor Litoral Centro-Norte, SC. 2010 b.

. Implantação do Plano Estadual de Gerenciamento Costeiro: Diagnóstico Socioambiental - Setor Litoral Norte, SC. 2010c.

Implantação do Plano Estadual de Gerenciamento Costeiro: Diagnóstico Socioambiental - Setor Litoral Centro-Sul, SC. 2010d.
Implantação do Plano Estadual de Gerenciamento Costeiro: Diagnóstico Socioambiental - Setor Litoral Sul, SC. 2010e.

Implantação do Plano Estadual de Gerenciamento Costeiro: Plano de Gestão Regional, SC. $2010 \mathrm{f}$.

UNEP - United Nations Environmental Programe. Guidelines for Integrated Management of Coastal and Marine Areas. UNEP Regional Seas Reports and Studies n ${ }^{\circ}$ 161, 1995.

Vianna, L. F. de N.; Bonetti, J.; POLETTE, M. Gestão costeira integrada: análise da compatibilidade entre os instrumentos de uma política pública para o desenvolvimento da maricultura e um plano de gerenciamento costeiro no Brasil. Revista de Gestão Costeira Integrada, 12(3), 357-372, set. 2012. DOI: $10.5894 / \mathrm{rgci} 335$. 